\title{
BMJ Open Antibiotic use and bacterial complications following upper respiratory tract infections: a population-based study
}

\author{
Thomas Cars, ${ }^{1}$ Irene Eriksson, ${ }^{1,2}$ Anna Granath, ${ }^{3,4}$ Björn Wettermark, ${ }^{1,2}$ \\ Jenny Hellman, ${ }^{5}$ Christer Norman, ${ }^{5}$ Anders Ternhag ${ }^{2,5}$
}

To cite: Cars T, Eriksson I, Granath $\mathrm{A}$, et al. Antibiotic use and bacterial complications following upper respiratory tract infections: a populationbased study. BMJ Open 2017;7:e016221. doi:10.1136/ bmjopen-2017-016221

- Prepublication history and additional material for this paper are available online. To view these files, please visit the journal online (http://dx.doi org/10.1136/bmjopen-2017016221).

Received 14 February 2017 Revised 4 August 2017

Accepted 15 September 2017

\section{(a) CrossMark}

${ }^{1}$ Department of Healthcare Development, Public Healthcare Services Committee, Stockholm County Council, Stockholm,

Sweden

${ }^{2}$ Department of Medicine Solna, Karolinska Institutet, Stockholm, Sweden

${ }^{3}$ Department of Clinical Science, Intervention and Technology, Karolinska Institutet, Stockholm, Sweden

${ }^{4}$ Ear, Nose and Throat Clinic, Karolinska University Hospital, Stockholm, Sweden

${ }^{5}$ Public Health Agency of

Sweden, Solna, Sweden

Correspondence to

Dr Thomas Cars;

thomas.cars@medsci.uu.se

\section{ABSTRACT}

Objectives To investigate if use of antibiotics was associated with bacterial complications following upper respiratory tract infections (URTIS).

Design Ecological time-trend analysis and a prospective cohort study.

Setting Primary, outpatient specialist and inpatient care in Stockholm County, Sweden. All analyses were based on administrative healthcare data on consultations, diagnoses and dispensed antibiotics from January 2006 to January 2016.

Main outcome measures Ecological time-trend analysis: 10-year trend analyses of the incidence of URTIs, bacterial infections/complications and respiratory antibiotic use. Prospective cohort study. Incidence of bacterial complications following URTIs in antibiotic-exposed and non-exposed patients.

Results The utilisation of respiratory tract antibiotics decreased by $22 \%$ from 2006 to 2015 , but no increased trend for mastoiditis $(p=0.0933)$, peritonsillar abscess $(p=0.0544)$, invasive group A streptococcal disease $(p=0.3991)$, orbital abscess $(p=0.9637)$, extradural and subdural abscesses $(p=0.4790)$ and pansinusitis $(p=0.3971)$ was observed. For meningitis and acute ethmoidal sinusitis, a decrease in the numbers of infections from 2006 to 2015 was observed ( $p=0.0038$ and $p=0.0003$, respectively), and for retropharyngeal and parapharyngeal abscesses, an increase was observed $(p=0.0214)$. Bacterial complications following URTIs were uncommon in both antibiotic-exposed (less than 1.5 per 10000 episodes) and non-exposed patients (less than 1.3 per 10000 episodes) with the exception of peritonsillar abscess after tonsillitis (risk per 10000 tonsillitis episodes: 32.4 and 41.1 in patients with no antibiotic treatment and patients treated with antibiotics, respectively).

Conclusions Bacterial complications following URTIs are rare, and antibiotics may lack protective effect in preventing bacterial complications. Analyses of routinely collected administrative healthcare data can provide valuable information on the number of URTIs, antibiotic use and bacterial complications to patients, prescribers and policy-makers.

\section{INTRODUCTION}

The use of antibiotics contributes to the emergence and spread of drug-resistant
Strengths and limitations of this study

- Data used in this study are population-based and include information from primary, outpatient specialist and inpatient care as well as data on all drugs dispensed in ambulatory care.

- Data are continuously updated, and loss to followup is minimal (only when an individual moves out of the region).

- Antibiotic exposure assessment is based on the information from a drug dispensation database; no data on antibiotics administered in hospitals were available for these analyses.

- Outcome definitions are based on recorded diagnoses. Thus, this study relies on the accuracy and completeness of diagnoses data.

- It is unknown whether the individual completed the prescribed course of antibiotic treatment.

bacteria. $^{1-3}$ Curbing antibiotic resistance requires coordinated action at the global, national and regional level. ${ }^{4}$ In Sweden, a comparatively low level of antibiotic utilisation has been achieved through years of strategic work at the national and regional level that have included surveillance of antibiotic utilisation $^{5}{ }^{6}$ and resistance trends, development and implementation of treatment guidelines as well as educational activities targeted at healthcare professionals, patients and the general public. ${ }^{7}$

Most antibiotics prescribed in the Swedish primary care are used for treatment of respiratory tract infections. ${ }^{8}$ Over the past 20 years, such use in Sweden has gradually declined. ${ }^{9}$ Most of this decline has been attributed to limiting the inappropriate antibiotic use in viral respiratory tract infections or mild selfhealing bacterial infections ${ }^{10}$ by the implementation of stricter guidelines, for example, for pharyngotonsillitis and acute otitis media (AOM).${ }^{11-13}$ However, we know that a substantial number of antibiotic prescriptions are 
still issued by doctors 'just in case' in fear of complications. ${ }^{14}{ }^{15}$ There is therefore a need for large studies on rare complications of upper respiratory tract infections (URTIs) in order to quantify these risks and hopefully to reduce some of the uncertainty for primary care physicians and their patients.

The objective of this study was to investigate if use of antibiotics was associated with bacterial complications following URTIs. First, we present results from an ecological time-trend analysis assessing whether the reduction in antibiotic use in URTIs was associated with a change in the incidence of bacterial complications in a large geographically defined population. Second, we present findings from a prospective cohort study based on individual patient level data describing the incidence of bacterial complications in antibiotic-exposed and non-exposed patients with URTIs.

\section{METHODS}

\section{Setting}

We conducted both an ecological time-trend analysis and a prospective cohort study in Stockholm County, Sweden, using administrative healthcare data from 1 January 2006 to 31 January 2016. Since this study used only anonymised administrative healthcare data, informed consent was not required. The study was approved by the regional ethics committee in Stockholm, Sweden (ref. no 2015/158-31).

\section{Data sources}

We used data from the regional healthcare data warehouse of Stockholm County (VAL) ${ }^{16}$ and the Swedish Prescribed Drug Register. ${ }^{17}$ VAL contains comprehensive administrative healthcare data for all Stockholm County residents (around 2.3 million people, approximately $23 \%$ of the population of Sweden). Virtually all healthcare contacts financed by the Stockholm County Council are documented in VAL. From VAL, we obtained the following information: demographic data (patient age and sex), diagnoses in primary care, outpatient specialist and inpatient care (diagnoses are coded using the International Classification of Diseases, 10th Revision (ICD10) codes), consultation dates (for both in-person and phone consultations), hospital admission and discharge dates, as well as migration and death records. From the Swedish Prescribed Drug Register, we obtained data on dispensed antibiotics (drugs are coded using the Anatomical Therapeutic Chemical codes).

\section{Ecological time-trend analysis}

For the ecological time-trend analysis, we used aggregate level antibiotic utilisation data (exposure) and data on the incidence of bacterial complications (outcome) between 1 January 2006 and 31 December 2015. We also assessed data on the incidence of URTIs during this period. We matched the exposure and outcome data based on the year in which they were recorded. The list of antibiotics classified as those used to treat URTIs is provided in online supplement 1 . The utilisation of antibiotics was expressed as the defined daily dose (DDD) per 1000 inhabitants per day (DID). ${ }^{18}$

We studied the following bacterial complications: mastoiditis, meningitis, retropharyngeal and parapharyngeal abscesses, invasive group A streptococcal disease, acute pansinusitis, acute ethmoidal sinusitis, orbital abscess, extradural abscess and subdural abscess documented in inpatient care. For peritonsillar abscess, diagnoses recorded both in outpatient and in inpatient care were included. The lists of ICD-10 codes used to define bacterial complications and primary URTIs are provided in online supplements 2 and 3, respectively.

\section{Prospective cohort study}

\section{Inclusion and exclusion criteria}

In the prospective cohort study, we included all patients with a diagnosis of AOM, tonsillitis, sinusitis or acute URTIs of multiple and unspecified sites diagnosed in the outpatient care (primary or outpatient specialist care) from 1 January 2006 to 31 December 2015 (see online supplement 3 for ICD-10 codes used to define the cohorts). The selected population was stratified into four subcohorts to study the incidence of bacterial complications in the antibiotic-exposed and non-exposed individuals: (1) AOM cohort to study the incidence of mastoiditis and meningitis, (2) tonsillitis cohort to study the incidence of peritonsillar abscess, retropharyngeal and parapharyngeal abscesses and invasive group A streptococcal disease, (3) acute sinusitis cohort to study the incidence of acute pansinusitis, orbital abscess and extradural and subdural abscesses and (4) a combined cohort of patients with sinusitis and acute URTIs (corresponding to the ICD-10 code: J06) to study the incidence of orbital cellulitis (without formation of abscess). This last combination cohort allowed to identify complications to acute rhinosinusitis, mainly of ethmoidal origin not included in the acute sinusitis cohort (the majority of this combination cohort is composed of children). In the widespread Swedish clinical practice, children displaying symptoms and signs of an orbital complication in relation to URTI (often of viral origin) are designated as cases of acute ethmoidal sinusitis (or other types of acute sinusitis) based on the clinical findings. ${ }^{19}$ In this paper and internationally, these complications are referred to as orbital cellulitis. The cohort selection flow chart can be found in online supplement 4 .

\section{Episode definition}

As more than one diagnosis of URTI can be recorded for the same patient, an episode was created to combine data on diagnoses and treatment attributed to the same URTI, and the start and the end dates were defined for each episode (figure 1).

The episode start date (index date) was defined as the date of the first recorded diagnosis within the episode. If there was more than a month (30-day period used in all calculations) between diagnoses, the later diagnosis 


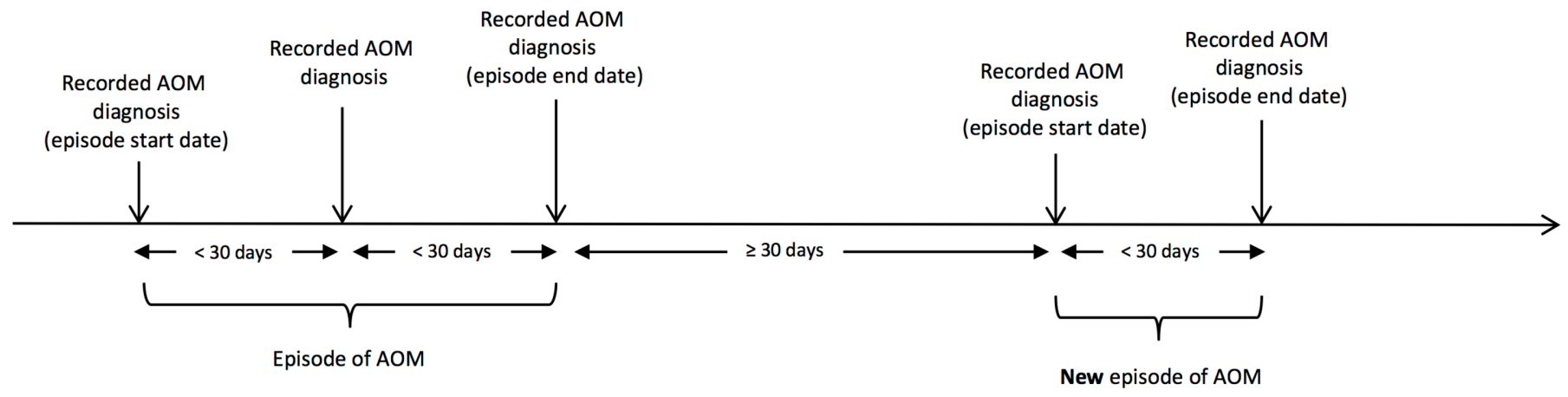

Figure 1 Definition of an episode of upper respiratory tract infection (here exemplified with acute otitis media (AOM)).

was attributed to a new URTI episode. The 30-day period was based on the Swedish guidelines on URTIs (sinusitis, AOM and tonsillitis) stating that new symptoms within 30 days are a relapse and not a new episode. If a dispensation of antibiotic occurred within 3 days after the latest recorded diagnosis attributed to an episode (reflecting the strategy of watchful waiting), the date of antibiotic dispensation constituted the episode end date. If a bacterial complication occurred, the date of complication diagnosis constituted the episode end date.

If a bacterial complication occurred on the same date as the episode start date, this episode was excluded from our analyses. Furthermore, episodes with less than 1 month of follow-up were also excluded.

For all bacterial complications, if more than 6 months passed between recorded diagnoses, it was defined as an incident bacterial complication. The 6-month period was chosen in order to not miss any late bacterial complications.

\section{Exposure groups}

Patients were considered exposed to respiratory tract antibiotics if a prescription was dispensed within the episode. An episode was not considered exposed to antibiotic if the first antibiotic prescription was dispensed on the same day as the bacterial complication.

\section{Outcomes}

The follow-up of patients for study outcomes started at the episode start date and continued for a 1-month period (30 days) after the episode end date.

The study outcomes included: (1) mastoiditis and meningitis diagnosed in inpatient care (AOM cohort); (2) peritonsillar abscess diagnosed in either outpatient or inpatient care, retropharyngeal and parapharyngeal abscesses and invasive group A streptococcal disease diagnosed in inpatient care (tonsillitis cohort); (3) pansinusitis, orbital abscess and extradural and subdural abscesses diagnosed in inpatient care (sinusitis cohort) and (4) orbital cellulitis diagnosed in inpatient care (sinusitis and acute URTIs (corresponding to the ICD-10 code: J06) in combination cohort). ICD-10 codes used to define bacterial complications are provided in online supplement 2. We included as outcomes in the study those bacterial complications that have an established or plausible association with URTIs.

\section{STATISTICAL ANALYSES}

For the time-trend analysis, aggregate level of respiratory antibiotic utilisation data (DDD per 1000 DID), number of bacterial complications per year as well as number of primary URTI episodes per year were plotted over time.

Trends for bacterial complications and respiratory antibiotic utilisation (using DDD as the measure of utilisation) were investigated using negative binomial regression models with annual Stockholm County population counts (as of 31 December each year) as the offset variable.

For the prospective cohort study, we calculated the number of patients experiencing episodes of URTIs and stratified these patients by age and antibiotic treatment (no antibiotic treatment group and treated with antibiotics group). We then calculated the number of bacterial complications occurring in these patients and risk of bacterial complications per 10000 episodes.

Data management and analyses were carried out using SAS 9.4 (SAS Institute, Cary, North Carolina, USA).

\section{RESULTS}

The volumes of dispensed respiratory tract antibiotics in Stockholm County declined by 22\% from 2006 to 2015 (figure 2). The number of AOM and sinusitis episodes declined, and the number of tonsillitis episodes was increasing from 2006 to 2012 and then sharply declined and remained stable from 2013 to 2015 (table 1). The proportion of patients treated with antibiotics declined in the cohorts of AOM (from $88 \%$ in 2006 to $81 \%$ in 2015), sinusitis (from $86 \%$ in 2006 to $71 \%$ in 2015 ) and sinusitis/acute URTI unspecified (from $36 \%$ in 2006 to $18 \%$ in 2015) and remained stable for tonsillitis (73\% in 2006 and $73 \%$ in 2015).

In the ecological time-trend analysis, we observed a significant decrease in the volumes of dispensed antibiotics from 2006 to 2015 ( $\mathrm{p}<0.0001)$. During the same time period, there was no significant trend in the number of the following bacterial complications: mastoiditis $(p=0.0933)$, 


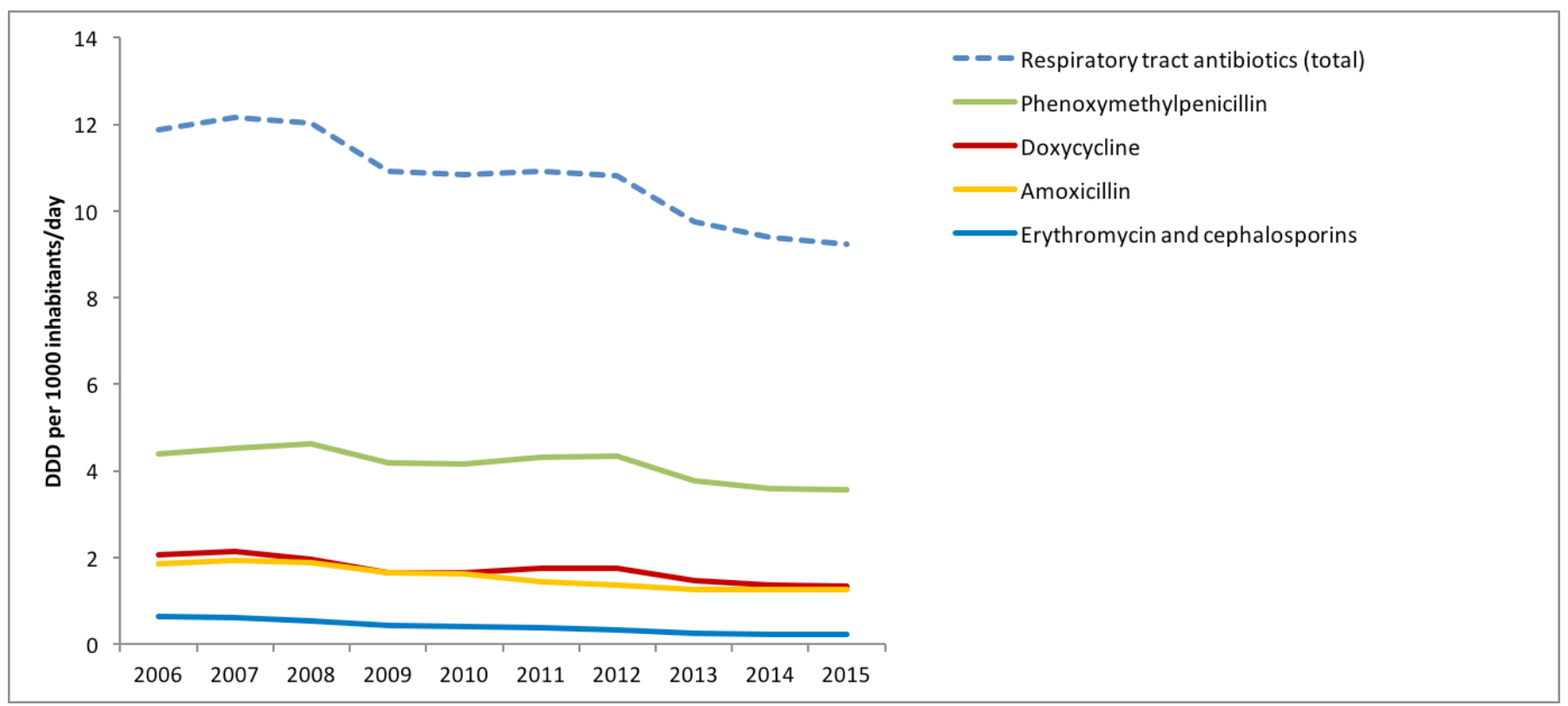

Figure 2 Trend for respiratory tract antibiotic utilisation in Stockholm County from 2006 to 2015. DDD, defined daily dose.

peritonsillar abscess $(\mathrm{p}=0.0544)$, invasive group A streptococcal disease $(\mathrm{p}=0.3991)$, orbital abscess $(\mathrm{p}=0.9637)$, extradural and subdural abscesses $(\mathrm{p}=0.4790)$ and pansinusitis $(\mathrm{p}=0.3971)$. For meningitis and acute ethmoidal sinusitis, a decrease in the numbers of infections from 2006 to 2015 was observed $(\mathrm{p}=0.0038$ and $\mathrm{p}=0.0003$, respectively), and for retropharyngeal and parapharyngeal abscesses, an increase was observed $(\mathrm{p}=0.0214)$. Data are presented in figure 3 .

Using individual patient level data, we identified 515 156 AOM, 866378 tonsillitis, 269215 sinusitis and 2 015595 sinusitis/acute URTIs of multiple and unspecified site episodes (see online supplement 4 for cohort selection flow charts). Table 2 provides information on the number of bacterial complications, stratified by age and antibiotic treatment. Our data showed that all bacterial complications in URTI patients were infrequent (less than 1.5 per 10000 episodes) with the exception of peritonsillar abscess after tonsillitis (risk per 10000 tonsillitis episodes: 32.4 and 41.1 in patients with no antibiotic treatment and patients treated with antibiotics, respectively). Peritonsillar abscess was most common in adults aged 15 to 64 years (risk per 10000 tonsillitis episodes: : 42.2 and 67.4 in patients with no antibiotic treatment and patients treated with antibiotics, respectively).

Table 1 Number of episodes and antibiotic treatment for AOM (cohort 1), tonsillitis (cohort 2), sinusitis (cohort 3) and sinusitis/ acute URTIs of multiple and unspecified sites in combination (cohort 4) in Stockholm County from 2006 to 2015

\begin{tabular}{|c|c|c|c|c|c|c|c|c|}
\hline & \multicolumn{2}{|l|}{ AOM } & \multicolumn{2}{|l|}{ Tonsillitis } & \multicolumn{2}{|l|}{ Sinusitis } & \multicolumn{2}{|c|}{$\begin{array}{l}\text { Sinusitis/acute URTI } \\
\text { unspecified }\end{array}$} \\
\hline & $\begin{array}{l}\text { No antibiotic } \\
\text { treatment }\end{array}$ & $\begin{array}{l}\text { Treated with } \\
\text { antibiotics }\end{array}$ & $\begin{array}{l}\text { No antibiotic } \\
\text { treatment }\end{array}$ & $\begin{array}{l}\text { Treated with } \\
\text { antibiotics }\end{array}$ & $\begin{array}{l}\text { No } \\
\text { antibiotic } \\
\text { treatment }\end{array}$ & $\begin{array}{l}\text { Treated with } \\
\text { antibiotics }\end{array}$ & $\begin{array}{l}\text { No antibiotic } \\
\text { treatment }\end{array}$ & $\begin{array}{l}\text { Treated with } \\
\text { antibiotics }\end{array}$ \\
\hline & $\mathrm{n}, \%$ & $\mathrm{n}, \%$ & $\mathrm{n}, \%$ & $\mathrm{n}, \%$ & $\mathrm{n}, \%$ & $\mathrm{n}, \%$ & $\mathrm{n}, \%$ & $\mathrm{n}, \%$ \\
\hline 2006 & $6414(12)$ & 47657 (88) & $20496(27)$ & $54998(73)$ & 3744 (14) & $23586(86)$ & 108735 (64) & $61658(36)$ \\
\hline 2008 & $8374(13)$ & 55350 (87) & 25857 (27) & 71041 (73) & 5065 (17) & 25057 (83) & 138906 (69) & 62195 (31) \\
\hline 2009 & 8260 (15) & $47543(85)$ & 27007 (29) & $67040(71)$ & $5942(22)$ & 21440 (78) & $149417(74)$ & $51323(26)$ \\
\hline 2010 & 10266 (18) & 47248 (82) & 27024 (28) & 68774 (72) & $7361(26)$ & $20737(74)$ & $160610(76)$ & 52044 (24) \\
\hline 2011 & $8773(18)$ & 41111 (82) & 23635 (25) & $70060(75)$ & $7531(28)$ & 19497 (72) & 167915 (77) & 50351 (23) \\
\hline 2012 & 9464 (19) & 39697 (81) & 24299 (24) & 78428 (76) & $8377(30)$ & $19988(70)$ & $172164(78)$ & 49398 (22) \\
\hline 2006-2015 & 82584 (16) & 435362 (84) & 232399 (27) & 637657 (73) & 62936 (23) & 207400 (77) & 1515985 (75) & 511507 (25) \\
\hline
\end{tabular}

AOM, acute otitis media; URTI, upper respiratory tract infection. 

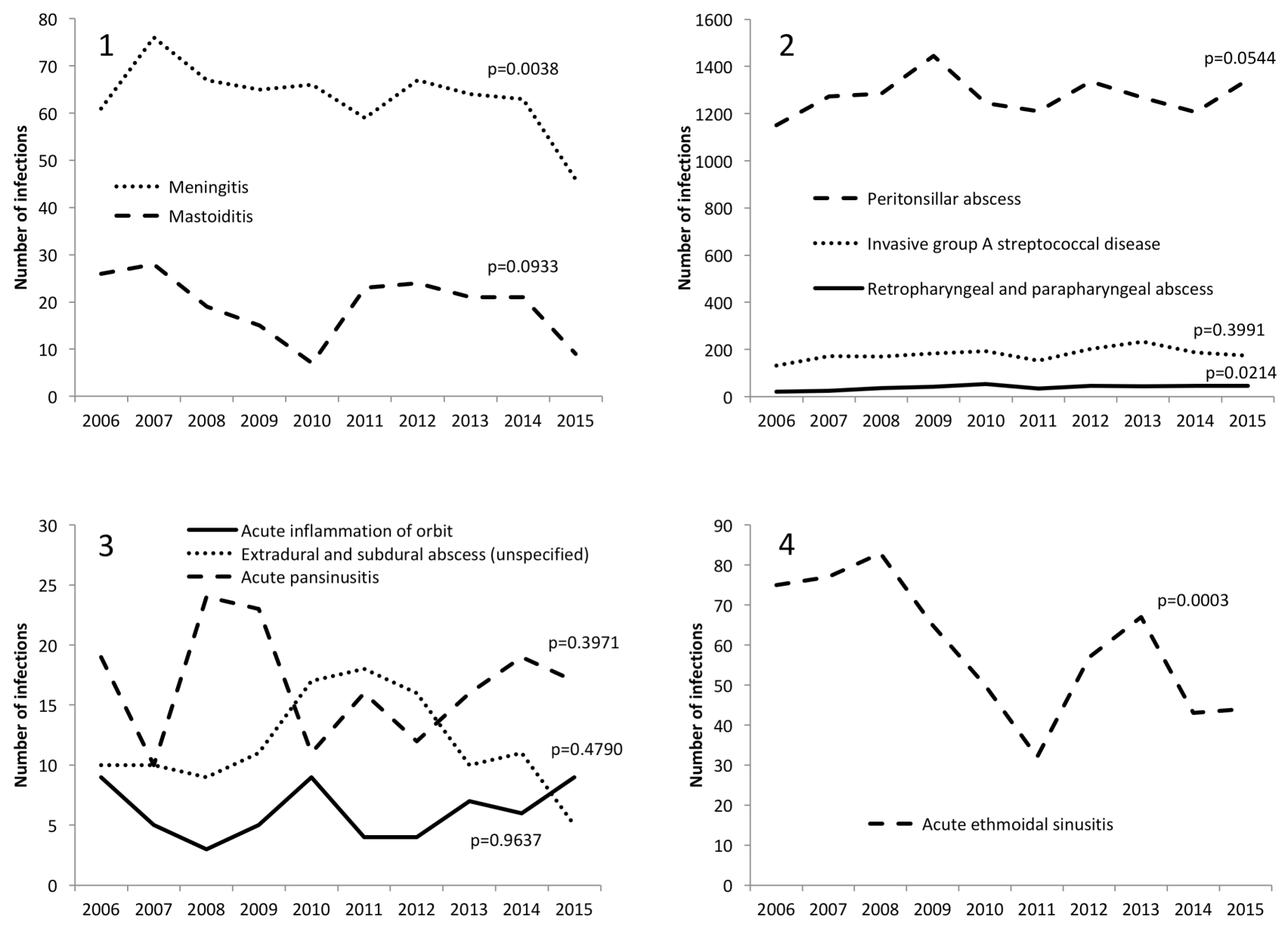

Figure 3 presents trends for bacterial complications in Stockholm County from 2006 to 2015 . The four panels (1-4) correspond to the complications we also assess in the four cohorts of the prospective cohort study (1) acute otitis media cohort, (2) tonsillitis cohort, (3) sinusitis cohort and (4) sinusitis and acute upper respiratory tract infections of multiple and unspecified site cohorts. p-values present test for trend.

Figure 3 Trend for bacterial complications in Stockholm County from 2006 to 2015.

\section{DISCUSSION}

The volumes of dispensed URTI antibiotics in Stockholm County decreased by 22\% over a 10-year period from 2006 to 2015. Our ecological time-trend analysis covering the entire population in a large region showed that restricted use of antibiotics was not associated with an increase in bacterial complications of mastoiditis, meningitis, peritonsillar abscess, invasive group A streptococcal disease, acute pansinusitis, acute ethmoidal sinusitis, orbital abscess and extradural abscess and subdural abscess. Moreover, the number of meningitis and acute ethmoidal sinusitis complications decreased over the study period. For retropharyngeal and parapharyngeal abscesses, an increase was observed.

The analyses of individual patient level data revealed that the incidence of bacterial complications following primary URTIs was very low: the risk per 10000 URTI episodes was less than 1.5 (average for all age groups) for all analysed bacterial complications (with the exception of peritonsillar abscess) for both patients with no antibiotic treatment and patients treated with antibiotics. We observed a slightly higher risk of bacterial complications in the antibiotic treated group in 3 out of 9 bacterial complications studied. This can possibly be explained by the presence of confounding by indication: patients prescribed antibiotics likely had a more severe primary URTI, thus were at a higher risk of both being prescribed an antibiotic and progressing to bacterial complications.

Our findings of no association between more restricted antibiotic use and the incidence of bacterial complications are in line with previous studies. ${ }^{10-22}$ A previous Swedish study ${ }^{23}$ showed that there was no increase in acute mastoiditis since 2000, when new guidelines recommending restrictive use of antibiotics for AOM were introduced. In 2010, new revised guidelines with an even more restrictive recommendation were issued..$^{24}$ Our study includes data on mastoiditis in Stockholm County before and after these most restrictive recommendations, thus providing a first update on the impact of further restriction of antibiotic use in the treatment of AOM. Of interest also is that while the proportion of patients with tonsillitis, sinusitis and other URTI receiving antibiotics in our study was comparable with that of Norway ${ }^{25}$ the doctors in Stockholm prescribed antibiotics to a larger proportion of AOM patients than the doctors in Norway did. This may possibly be explained by different frameworks for coding 
Open Access

Table 2 Risk of bacterial complications in the month after diagnosis of URTIs

No antibiotic treatment
No of
episodes No of complications Risk per 10000

Treated with antibiotics

No of

episodes

No of complications Risk per 10000

\section{Mastoiditis after AOM}

$\begin{array}{lllllll}0-4 & 45473 & 6 & 1.32 & 243141 & 23 & 0.95 \\ 5-14 & 21294 & 3 & 1.41 & 88741 & 13 & 1.46 \\ 15-64 & 12676 & 1 & 0.79 & 93582 & 9 & 0.96 \\ 65+ & 2412 & 0 & - & 7809 & 1 & 1.28 \\ \text { Total }^{*} & 81864 & 10 & 1.22 & 433273 & 46 & 1.06\end{array}$

Meningitis after AOM

$\begin{array}{llllllll}0-4 & 45476 & 2 & 0.44 & 243151 & 1 & 0.04 \\ 5-14 & 21292 & 1 & 0.47 & 88746 & 0 & - \\ 15-64 & 12676 & 1 & 0.79 & 93581 & 13 & 1.39 \\ 65+ & 2412 & 0 & - & 7808 & 4 & 5.13 & 0.42 \\ \text { Total }^{*} & 81865 & 4 & 0.49 & 433286 & 18 & \end{array}$

Peritonsilitis after pharyngotonsillitis

\begin{tabular}{lllllll}
$0-4$ & 20772 & 4 & 1.93 & 116785 & 15 & 1.28 \\
\hline $5-14$ & 44609 & 57 & 12.8 & 156170 & 183 & 11.7 \\
$15-64$ & 157178 & 663 & 42.2 & 347424 & 2340 & 67.4 \\
$65+$ & 9167 & 27 & 29.5 & 12552 & 61 & 48.6 \\
Total† & 231749 & 751 & 32.4 & 632933 & 2599 & 41.1
\end{tabular}

Retropharyngeal and parapharyngeal abscesses after pharyngotonsillitis

\begin{tabular}{lllllll}
$0-4$ & 20772 & 0 & - & 116811 & 2 & 0.17 \\
\hline $5-14$ & 44585 & 0 & - & 156332 & 3 & 0.19 \\
$15-64$ & 156805 & 24 & 1.53 & 349240 & 76 & 2.18 \\
$65+$ & 9154 & 4 & 4.37 & 12627 & 9 & 7.13 \\
Total $\dagger$ & 231339 & 28 & 1.21 & 635012 & 90 & 1.42
\end{tabular}

Invasive group A streptococcal disease after pharyngotonsillitis

$\begin{array}{lllllll}0-4 & 20772 & 0 & - & 116811 & 0 & - \\ 5-14 & 44585 & 0 & - & 156333 & 2 & 0.13 \\ 15-64 & 156806 & 4 & 0.26 & 349255 & 8 & 0.23 \\ 65+ & 9155 & 3 & 3.28 & 12632 & 1 & 0.79 \\ \text { Total } \dagger & 231341 & 7 & 0.30 & 635033 & 11 & 0.17\end{array}$

Orbital abscess after sinusitis

$\begin{array}{lllllll}0-4 & 199 & 0 & - & 679 & 0 & - \\ 5-14 & 1791 & 1 & 5.58 & 4333 & 0 & - \\ 15-64 & 54811 & 0 & - & 181930 & 1 & 0.05 \\ 65+ & 5637 & 0 & - & 19832 & 0 & - \\ \text { Totalł } & 62441 & 1 & 0.16 & 206774 & 1 & 0.05\end{array}$

Extradural and subdural abscesses after sinusitis

\begin{tabular}{lllllll}
$0-4$ & 199 & 0 & - & 679 & 0 & - \\
$5-14$ & 1791 & 0 & - & 4333 & 1 & 2.31 \\
$15-64$ & 54811 & 1 & 0.18 & 181930 & 1 & 0.05 \\
$65+$ & 5637 & 0 & - & 19832 & 0 & - \\
Total & 62441 & 1 & 0.16 & 206774 & 2 & 0.10 \\
\hline
\end{tabular}

Continued 
Table 2 Continued

\begin{tabular}{llll} 
No antibiotic treatment & \multicolumn{2}{l}{ Treated with antibiotics } \\
\cline { 1 - 2 } $\begin{array}{lll}\text { No of } \\
\text { episodes }\end{array} \quad$ No of complications Risk per 10000 & & episodes & No of complications Risk per 10000
\end{tabular}

\begin{tabular}{|c|c|c|c|c|c|c|}
\hline \multicolumn{7}{|c|}{ Acute pansinusitis after sinusitis } \\
\hline $0-4$ & 198 & 0 & - & 679 & 0 & - \\
\hline $5-14$ & 1790 & 0 & - & 4330 & 1 & 2.31 \\
\hline $65+$ & 5637 & 0 & - & 19832 & 2 & 1.01 \\
\hline Totalł & 62440 & 7 & 1.12 & 206764 & 18 & 0.87 \\
\hline \multicolumn{7}{|c|}{ Acute ethmoidal sinusitis after sinusitis/acute URTIs of multiple and unspecified sites } \\
\hline $0-4$ & 419540 & 39 & 0.93 & 70887 & 15 & 2.12 \\
\hline $5-14$ & 208157 & 21 & 1.01 & 34173 & 13 & 3.80 \\
\hline $15-64$ & 778900 & 4 & 0.05 & 347041 & 6 & 0.17 \\
\hline $65+$ & 100201 & 1 & 0.10 & 56669 & 0 & - \\
\hline Total§ & 1506825 & 65 & 0.43 & 508770 & 34 & 0.67 \\
\hline
\end{tabular}

*Missing information on age for 9 episodes of AOM.

†Missing information on age for 25 episodes of tonsillitis.

¥Missing information on age for 3 episodes of sinusitis.

\$Missing information on age for 27 episodes of sinusitis.

AOM, acute otitis media; URTI, upper respiratory tract infection.

AOM (ICD-10 vs International Classification of Primary Care) and different definitions for exposure to antibiotic. Our definition of the antibiotic-exposed group included patients receiving an antibiotic anytime during their URTI episode, thus likely resulting in a more complete capture of patients treated with antibiotics. Differences in definitions used can also explain discrepancies with other observational studies. ${ }^{20}{ }^{26}$ For example, our definition of bacterial complication only included bacterial complications recorded in inpatient care (except for peritonsillar abscess) and, therefore, was stricter than those used in other studies (eg, in comparison to analyses by Petersen et $a l)$.

We found that a large proportion of diagnosed bacterial complications analysed in this study were not preceded by patients seeking care for URTIs. A short duration from the onset of primary URTI to progression to bacterial complication could be an explanation for this as patient would have already developed a bacterial complication by the time of the first contact with healthcare professionals. In children, for example, the onset of symptoms and signs of mastoiditis is often very quick (within 24 hours). In this case, a rapid progress of the disease is likely related to the virulence of pathogenic airway bacteria. It has also been noted that peritonsillar abscess, the most common bacterial complication among adults in our study, often occurs without a preceding typical tonsillitis. ${ }^{27}$ Alternate routes of infection, for example, oral pathogenic bacteria, may play a role in the aetiology of peritonsillar abscess.

The decline in meningitis and acute ethmoidal sinusitis observed in our analyses is in line with previous studies demonstrating a similar decrease in these infections after the introduction of conjugated antipneumococcal vaccine in the general vaccine schedule in Stockholm in $2007{ }^{28}$ Retropharyngeal and parapharyngeal abscesses are uncommon diseases, and it was outside of the scope of this study to investigate what may have contributed to the discreet increase in these complications observed during the study period. Among risk factors for these heterogeneous infections are local trauma, immunosuppression and dental infections. ${ }^{29}$

All data used in our study are population-based and include information on diagnoses in primary, outpatient specialist and inpatient care as long as they were recorded by healthcare professionals, as well as on all dispensations of antibiotics in ambulatory care. These data are updated on a monthly basis, thus enabling a real-time patient follow-up. We based our selection of bacterial complications on those that we perceived have an established association with URTIs. There could be other bacterial complications such as pneumonia that we have missed by narrowing the number of complications we looked for. Furthermore, using administrative data in general carries a number of known limitations, including reliance on the accuracy and completeness of recorded diagnoses, lack of information on antibiotics administered in hospitals and inability to assert whether the patient completed the prescribed course of antibiotic treatment.

To summarise, our study demonstrated that routinely collected administrative healthcare data can provide valuable information on the number of URTIs, antibiotic use and bacterial complications to patients, prescribers and policy-makers. We found that bacterial complications were rare both in patients with no antibiotic treatment 
and in patients treated with antibiotics. While the utilisation of respiratory tract antibiotics decreased, bacterial complications following URTIs remained uncommon.

Acknowledgements Ahmed Farah at the Public Health Agency of Sweden is acknowledged for statistical support

Contributors TC, IE, AG, BW, JH, CN and AT contributed to the design of the study. TC extracted the data, wrote statistical programs and led statistical analyses. TC, IE, AG, BW, JH, CN and AT participated in the interpretation of data. TC had full access to all of the data in the study and can take responsibility for the integrity of the data and the accuracy of the data analysis. TC and IE drafted the paper. TC, IE, AG, BW, $\mathrm{JH}, \mathrm{CN}$ and $\mathrm{AT}$ critically revised the paper for important intellectual content and approved the final version to be published.

Funding This study was funded by the Stockholm County Council and the Public Health Agency of Sweden.

Competing interests None declared.

Ethics approval The study was approved by the regional ethics committee at Karolinska Institutet, Sweden (ref. no 2015/158-31).

Provenance and peer review Not commissioned; externally peer reviewed.

Data sharing statement Additional data are available by emailing the corresponding author.

Open Access This is an Open Access article distributed in accordance with the Creative Commons Attribution Non Commercial (CC BY-NC 4.0) license, which permits others to distribute, remix, adapt, build upon this work non-commercially, and license their derivative works on different terms, provided the original work is properly cited and the use is non-commercial. See: http://creativecommons.org/ licenses/by-nc/4.0/

(C) Article author(s) (or their employer(s) unless otherwise stated in the text of the article) 2017. All rights reserved. No commercial use is permitted unless otherwise expressly granted.

\section{REFERENCES}

1. Bronzwaer SL, Cars O, Buchholz U, et al. A European study on the relationship between antimicrobial use and antimicrobial resistance. Emerg Infect Dis 2002;8:278-82.

2. Goossens H, Ferech M, Vander Stichele R, et al. Outpatient antibiotic use in Europe and association with resistance: a cross-national database study. Lancet 2005;365:579-87.

3. Costelloe C, Metcalfe C, Lovering A, et al. Effect of antibiotic prescribing in primary care on antimicrobial resistance in individual patients: systematic review and meta-analysis. BMJ 2010;340:c2096.

4. Kaplan W, Wirtz V, Mantel-Teeuwisse A, et al. Priority mnedicines for Europe and the World 2013 update. Geneva: World Health Organization in collaboration with Utrecht University and Boston University, 2013.

5. Adriaenssens N, Coenen S, Versporten A, et al. ESAC Project Group. European Surveillance of Antimicrobial Consumption (ESAC): outpatient antibiotic use in Europe (1997-2009). J Antimicrob Chemother 2011;66(Suppl 6):vi3-12.

6. Van Boeckel TP, Gandra S, Ashok A, et al. Global antibiotic consumption 2000 to 2010: an analysis of national pharmaceutical sales data. Lancet Infect Dis 2014;14:742-50.

7. Mölstad S, Erntell M, Hanberger $\mathrm{H}$, et al. Sustained reduction of antibiotic use and low bacterial resistance: 10-year follow-up of the Swedish strama programme. Lancet Infect Dis 2008;8:125-32.

8. André M, Vernby A, Odenholt I, et al. Diagnosis-prescribing surveys in 2000, 2002 and 2005 in Swedish general practice: consultations, diagnosis, diagnostics and treatment choices. Scand $\mathrm{J}$ Infect Dis 2008;40:648-54.

9. Public Health Agency of Sweden. A report on Swedish Antibiotic Utilisation and Resistance in Human Medicine. SWEDRES 2013.

10. Keith T, Saxena S, Murray J, et al. Risk-benefit analysis of restricting antimicrobial prescribing in children: what do we really know? Curr Opin Infect Dis 2010;23:242-8.

11. Gunnarsson MS, Sundvall PD, Gunnarsson R. In primary health care, never prescribe antibiotics to patients suspected of having an uncomplicated sore throat caused by group A beta-haemolytic streptococci without first confirming the presence of this bacterium. Scand J Infect Dis 2012;44:915-21.

12. Centor RM. Antibiotics for sore throat patients-varied opinions. Scand J Infect Dis 2013;45:176-8.

13. Strömberg A, Roos K, Hagberg L. [Scrap the Centor criteria in tonsillitis]. Lakartidningen 2015;112.

14. Lucas PJ, Cabral C, Hay AD, et al. A systematic review of parent and clinician views and perceptions that influence prescribing decisions in relation to acute childhood infections in primary care. Scand $J$ Prim Health Care 2015;33:11-20.

15. Kumar S, Little P, Britten N. Why do general practitioners prescribe antibiotics for sore throat? Grounded theory interview study. BMJ 2003;326:138.

16. Wändell P, Carlsson AC, Wettermark B, et al. Most common diseases diagnosed in primary care in Stockholm, Sweden, in 2011. Fam Pract 2013;30:506-13.

17. Wettermark B, Hammar N, Fored CM, et al. The new Swedish prescribed drug Register-opportunities for pharmacoepidemiological research and experience from the first six months. Pharmacoepidemiol Drug Saf 2007;16:726-35.

18. Coenen S, Ferech M, Haaijer-Ruskamp FM, et al. European Surveillance of Antimicrobial Consumption (ESAC): quality indicators for outpatient antibiotic use in Europe. Qual Saf Health Care 2007;16:440-5.

19. Schollin Ask L, Hultman Dennison S, Stjärne P, et al. Most preschool children hospitalised for acute rhinosinusitis had orbital complications, more common in the youngest and among boys. Acta Paediatr 2017;106:268-73.

20. Petersen I, Johnson AM, Islam A, et al. Protective effect of antibiotics against serious complications of common respiratory tract infections: retrospective cohort study with the UK general practice research database. BMJ 2007;335:982.

21. Sharland $M$, Kendall $H$, Yeates $D$, et al. Antibiotic prescribing in general practice and hospital admissions for peritonsillar abscess, mastoiditis, and rheumatic fever in children: time trend analysis. $B M J$ 2005;331:328-9.

22. Hansen FS, Hoffmans R, Georgalas C, et al. Complications of acute rhinosinusitis in The Netherlands. Fam Pract 2012;29:147-53.

23. Groth A, Enoksson F, Hermansson A, et al. Acute mastoiditis in children in Sweden 1993-2007-no increase after new guidelines. Int $J$ Pediatr Otorhinolaryngol 2011;75:1496-501.

24. Behandlingsrekommendation-otit MPA. In Swedish. 2010 https://lakemedelsverketse/upload/halso-och-sjukvard/ behandlingsrekommendationer/Akutmediaotit_rek_webbpdf (accessed 11 May 2017).

25. Gjelstad S, Straand J, Dalen I, et al. Do general practitioners' consultation rates influence their prescribing patterns of antibiotics for acute respiratory tract infections? J Antimicrob Chemother 2011;66:2425-33.

26. Gulliford MC, Moore MV, Little P, et al. Safety of reduced antibiotic prescribing for self limiting respiratory tract infections in primary care: cohort study using electronic health records. BMJ 2016;354:i3410.

27. Marom T, Cinamon U, Itskoviz D, et al. Changing trends of peritonsillar abscess. Am J Otolaryngol 2010;31:162-7.

28. Lindstrand A, Bennet R, Galanis I, et al. Sinusitis and pneumonia hospitalization after introduction of pneumococcal conjugate vaccine. Pediatrics 2014;134:e1528-36.

29. Parhiscar A, Har-El G. Deep neck abscess: a retrospective review of 210 cases. Ann Otol Rhinol Laryngol 2001;110:1051-4. 